\title{
ARTICLE
}

\section{The behavior of advanced gas reactor simulated spent nuclear fuels in wet interim storage conditions}

\author{
Elizabeth A. Howett ${ }^{\mathrm{a}}$, Colin Boxall ${ }^{\mathrm{a}^{*}}$, Richard J. Wilbraham ${ }^{\mathrm{a}}$ and David I. Hambley ${ }^{\mathrm{b}}$ \\ ${ }^{a}$ Engineering Department, Lancaster University, Lancaster LA1 4YW, UK; ${ }^{b}$ Spent Fuel Management and Disposal, UK National \\ Nuclear Laboratory (NNL), Central Laboratory, Sellafield CA20 1PG, UK
}

\begin{abstract}
The safe interim storage of spent nuclear fuel is important to prevent the degradation of the containers and fuel rods - both fuel pellets and cladding - thus avoiding the release of radiation and allowing the fuel to be safely handled on transfer to a long term disposal facility. The corrosion of pure $\mathrm{UO}_{2}$ and UK Advanced Gas-cooled Reactor (AGR) simulated spent nuclear fuels (SIMFUELs) was studied under conditions typical of those found in interim spent fuel storage pond waters. With respect to the dissolution of spent fuel, it appears to be advantageous to dose the ponds to $\mathrm{pH} \approx 11.4$. The alkaline conditions in the pond water suppress the dissolution as $\mathrm{UO}_{2}{ }^{2+}$ which may otherwise occur at neutrality and lower $\mathrm{pHs}$.
\end{abstract}

Keywords: corrosion; uranium; wet interim storage

\section{Introduction}

The bulk of the UK's operating fleet of nuclear reactors are of the Advanced Gas-cooled Reactor type (AGR). These were constructed during the 1970s and 1980s and utilize a graphite moderator and $\mathrm{CO}_{2}$ gas coolant. AGR fuel consists of low enriched $\mathrm{UO}_{2}$ annular ceramic pellets, encased in a $20 / 25 / \mathrm{Nb}$ stainless steel cladding. Currently, spent nuclear fuel (SNF) from these reactors undergoes reprocessing at the Thermal Oxide Reprocessing Plant (THORP) in Sellafield, Cumbria, where the spent fuel components are separated. Unused uranium and plutonium can be sent to form new fuel, and the fission products present in the fuel can be removed for disposal as high-level waste.

However, THORP is due to close within the next 2 years. The plan for current holdings of un-reprocessed AGR SNF and SNF that will be discharged from AGRs in the future is to send it to a national Geological Disposal Facility (GDF). The intention is for the GDF to start taking intermediate level waste (ILW) in the late 2030s, with fuel to follow after the disposal of the bulk of the accumulated ILW. It is therefore likely that the GDF may not be open for receipt of spent fuel until around 2075. Until then UK AGR SNF will be kept in interim wet storage in ponds at Sellafield, ultimately being consolidated into a single, long term storage pond. Specifically, in order to accommodate all future AGR SNF arisings until such time as a permanent disposal facility becomes available, a new racking system for the THORP Receipt and Storage pond has been proposed.

*Corresponding author. Email: c.boxall@lancaster.ac.uk
This new arrangement will mean that fuel will be packed closer together, the resultant increase in decay heat output causing a rise in the temperature of pond water from the $24^{\circ} \mathrm{C}$ that which obtains in the current storage arrangement. Present assessments indicate that rack water temperature could rise to approximately $60^{\circ} \mathrm{C}$ with an average of around $45^{\circ} \mathrm{C}$ [1].

The fuel is currently and will continue to be stored in interim storage ponds containing demineralized water with a chloride concentration typically $<0.1 \mathrm{ppm}$. AGR SNF storage ponds currently have a temperature of $24^{\circ} \mathrm{C}$ and a $\mathrm{pH} \approx 11.4$, the latter achieved by dosing the pond with $\mathrm{NaOH}$ to inhibit corrosion. This storage regime has been shown to be effective for the safe storage of AGR fuel for up to $\sim 25$ years. Without such treatment, and specifically in the absence of $\mathrm{NaOH}$ as a corrosion inhibitor, cladding corrosion is observed, cladding perforation occurring within 1- 2 years in the presence of $0.2-0.3 \mathrm{ppm}$ chloride in inhibitor-free / undosed pond water [2]. For higher chloride concentrations of 1-10 ppm, perforation was observed after only 100-200 days [2]. Cladding perforation is undesirable as it results in exposure of the spent fuel pellets to pond water and thus undesirable contamination of the pond with highly radioactive soluble fission products.

Current storage periods are typically less than 10 years, although this may extend to as long as 100 years after THORP closes. It is therefore necessary to determine whether AGR SNF can be stored safely in the same manner as it is currently without significant degradation of the SNF over this extended time scale.

The AGR fuel cladding will be in direct contact with 
the pond water, however in the case that the cladding is breached due to stress corrosion cracking, an unexpected rise in chloride levels or in the unlikely event that the cladding has been damaged during dismantling of the fuel assembly the fuel itself will be exposed to the pond water. Therefore, it is essential to study both the evolution of the cladding and fuel surfaces under pond water conditions.

The purpose of the work reported here is to establish a baseline corrosion behavior of AGR SNF in simulant pond water, through study of the corrosion of pure $\mathrm{UO}_{2}$ and simulated AGR SNFs (AGR SIMFUELs) that have been especially fabricated for this work and whose development and characterization has been described previously, both in this issue and elsewhere [3-5].

\section{Experimental}

\subsection{Materials}

The UK National Nuclear Laboratory (NNL) fabricated $\mathrm{UO}_{2}$ pellets and SIMFUEL pellets simulating AGR fuel pellet burn-ups of $25 \mathrm{GWd} / \mathrm{tU}$ and 43 $\mathrm{GWd} / \mathrm{tU}$. SIMFUEL pellets were prepared using sintering powder precursors containing the dopant compositions given in Table 1. The composition calculations were conducted using the FISPIN nuclear inventory calculation code (developed by NNL and distributed by AMEC [6]) and represent fuel pellets that have been aged for 100 years after removal from the reactor. A detailed description of the fabrication process and materials characterization of the pellets can be found in Hiezl et al. [3].

Table 1. Composition of AGR SIMFUEL pellets with different burn-ups.

\begin{tabular}{ccc}
\hline Dopant & $\mathrm{wt} \% 25 \mathrm{GWd} / \mathrm{tU}$ & $\mathrm{wt} \% 43 \mathrm{GWd} / \mathrm{tU}$ \\
\hline $\mathrm{UO}_{2}$ & 95.705 & 92.748 \\
$\mathrm{Nd}_{2} \mathrm{O}_{3}$ & 0.761 & 1.284 \\
$\mathrm{ZrO}_{2}$ & 0.793 & 1.276 \\
$\mathrm{MoO}_{3}$ & 0.614 & 1.027 \\
$\mathrm{RuO}_{2}$ & 0.512 & 0.892 \\
$\mathrm{BaCo}_{3}$ & 0.328 & 0.576 \\
$\mathrm{CeO}_{2}$ & 0.297 & 0.499 \\
$\mathrm{PdO}$ & 0.195 & 0.425 \\
$\mathrm{Rh}_{2} \mathrm{O}_{3}$ & 0.080 & 0.115 \\
$\mathrm{La}_{2} \mathrm{O}_{3}$ & 0.156 & 0.256 \\
$\mathrm{SrO}$ & 0.081 & 0.126 \\
$\mathrm{Y}_{2} \mathrm{O}_{3}$ & 0.095 & 0.149 \\
$\mathrm{CsCO}_{3}$ & 0.311 & 0.495 \\
$\mathrm{TeO}_{2}$ & 0.073 & 0.130 \\
\hline
\end{tabular}

Pond water simulants were prepared in doubly deionized water to the specification given in Table 2 and dosed with hydroxide to a $\mathrm{pH} \approx 11.4$ where appropriate. The simulant composition given in Table 2 is based on the average of sample data from the AGR storage pond which was analyzed once a week from October to December 2013. N.B. these values are those of the current AGR storage pond not the THORP Receipt and Storage pond. However, analysis of the composition of the THORP pond during the same period suggests that use of the composition of Table 2 as a THORP pond water simulant would constitute a conservative approach.

Table 2. Simulant pond water composition.

\begin{tabular}{cc}
\hline Ion & Concentration $/ \mu \mathrm{mol} \mathrm{dm}{ }^{-3}$ \\
\hline $\mathrm{Na}^{+}$ & $5.4 \times 10^{3}$ \\
$\mathrm{Ca}^{2+}$ & 2 \\
$\mathrm{Cl}^{-}$ & 30 \\
$\mathrm{SO}_{4}^{2-}$ & 2 \\
$\mathrm{~K}^{+}$ & 5 \\
$\mathrm{OH}^{-}$ & $5.4 \times 10^{3}$ \\
\hline
\end{tabular}

\subsection{Electrode preparation}

The $\mathrm{UO}_{2}$ and SIMFUEL samples were mounted on brass bases and set in an epoxy resin mold to form a disk electrode. The surface of the sample was then polished using silicon carbide sandpaper (600 standard grit).

\subsection{Electrochemistry}

All electrochemical studies were carried out on a Metrohm Autolab potentiostat model PGSTAT128N using NOVA control and data acquisition software. A three-electrode cell was employed using a platinum mesh counter and a $\mathrm{Ag} / \mathrm{AgCl}$ electrode as the reference electrode.

Cyclic voltammetry (CV) studies on $\mathrm{UO}_{2}$ and SIMFUEL sample electrodes immersed in $0.5 \mathrm{M} \mathrm{Na}_{2} \mathrm{SO}_{4}$ or pond water simulants were carried out at a scan rate of $10 \mathrm{mV} / \mathrm{s}$ over a potential range of -1.8 to $0.4 \mathrm{~V}$. IR compensation was utilized during the voltammetric experiments on account of the resistive nature of $\mathrm{UO}_{2}$ and SIMFUEL electrodes.

Open circuit potential (OCP) measurements on the three samples immersed in $0.5 \mathrm{M} \mathrm{Na}_{2} \mathrm{SO}_{4}$, simulant pond water and a combination of $0.5 \mathrm{M} \mathrm{Na}_{2} \mathrm{SO}_{4}$ and $\mathrm{NaOH}$ solution were carried out for a 12 hour period using a two electrode cell with a $\mathrm{Ag} / \mathrm{AgCl}$ reference.

\section{Results}

In the first instance, to establish their baseline electrochemical behavior, $\mathrm{CV}$ experiments were carried out on the $\mathrm{UO}_{2}$ and two SIMFUEL samples in $0.5 \mathrm{M}$ $\mathrm{Na}_{2} \mathrm{SO}_{4}, \mathrm{pH} \approx 5.6$. These are shown in Figure 1, it is seen that the forward scans of each sample have three common peaks/regions. From the literature the origin of these peaks, seen in references [7,8], designated as peaks I to III with increasing applied potential, can be assigned as follows: peak I oxidation of $\mathrm{UO}_{2}$ to $\mathrm{UO}_{2+\mathrm{x}}$ at the grain boundaries; peak II oxidation of the bulk $\mathrm{UO}_{2}$ matrix to $\mathrm{UO}_{2+\mathrm{x}}$ with incorporation of $\mathrm{O}^{2-}$ ions into the lattice until a limiting stoichiometry of $\mathrm{UO}_{2.33}$ is attained; peak III oxidation of $\mathrm{UO}_{2+\mathrm{x}}$ to a $\mathrm{U}(\mathrm{VI})$ species such as soluble $\mathrm{UO}_{2}{ }^{2+}$ or insoluble $\mathrm{UO}_{3} \cdot \mathrm{yH}_{2} \mathrm{O}$ [9].

It has been previously reported in work on LWR SIMFUELs that the addition of lower valence species, such as trivalent rare earths, causes an increase in the 
electrical conductivity of the $\mathrm{UO}_{2}$ bulk matrix. This is due to the ionization of uranium ions to maintain charge balance which creates mobile holes in the $\mathrm{U} 5 \mathrm{f}$ band. This allows for the passage of higher electrochemical currents though LWR SIMFUELs than pure $\mathrm{UO}_{2}[10]$.

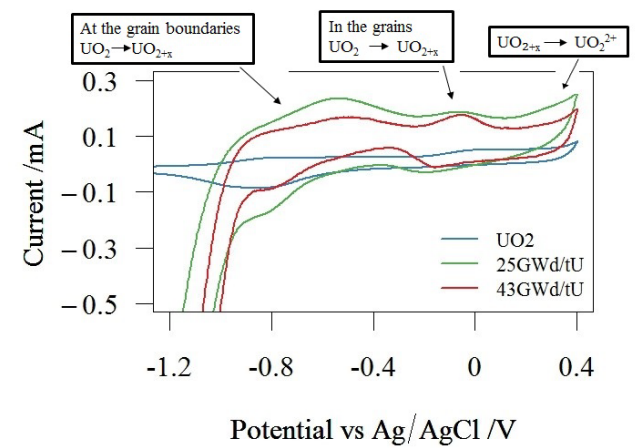

Figure 1. Cyclic Voltammetry of $\mathrm{UO}_{2}, 25$ and $43 \mathrm{GWd} / \mathrm{tU}$ SIMFUELs in $0.5 \mathrm{M} \mathrm{Na}_{2} \mathrm{SO}_{4}, \mathrm{pH} \approx 5.6$.

It can be seen from the CV results of Figure 1 that AGR SIMFUELs behave in a similar fashion. However, the currents associated with the higher burn-up SIMFUEL, $43 \mathrm{GWd} / \mathrm{tU}$, are unexpectedly lower than those of the $25 \mathrm{GWd} / \mathrm{tU}$ sample. It has been suggested by He et al that doping at higher lanthanide levels may stabilize the fluorite lattice against anodic oxidation and dissolution by decreasing the amount of vacancy sites free for $\mathrm{O}_{2}^{-}$incorporation [11] - and it may be this stabilization that is responsible for the suppressed oxidation currents observed from the $43 \mathrm{GWd} / \mathrm{tU}$ sample compared to the $25 \mathrm{GWd} / \mathrm{tU}$ sample in Figure 1.

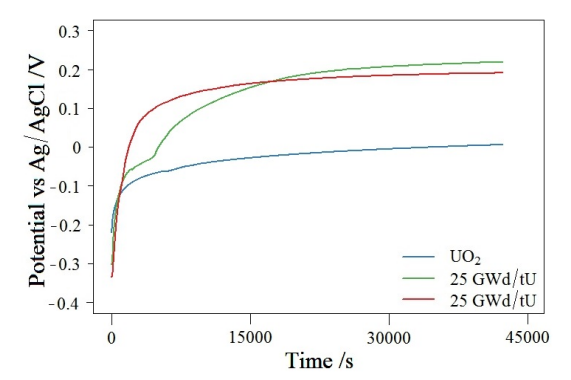

Figure 2. Open Circuit Potential measurements of $\mathrm{UO}_{2}, 25$ and $43 \mathrm{GWd} / \mathrm{tU}$ SIMFUELs in $0.5 \mathrm{M} \mathrm{Na}_{2} \mathrm{SO}_{4}, \mathrm{pH} \approx 5.6$.

The OCPs for the $\mathrm{UO}_{2}, 25 \mathrm{GWd} / \mathrm{tU}$ and $43 \mathrm{GWd} / \mathrm{tU}$ samples in $0.5 \mathrm{M} \mathrm{Na}_{2} \mathrm{SO}_{4}$ at $\mathrm{pH} \approx 5.6$ are observed to be $0.01 \mathrm{~V}, 0.22 \mathrm{~V}$ and $0.19 \mathrm{~V}$ respectively as shown in Figure 2. If these values are compared to their positions on the $\mathrm{CV}$ in Figure 1 it is seen that the OCP of pure $\mathrm{UO}_{2}$ sits on the anodic side of the current-voltage peak associated with the onset of the $\mathrm{UO}_{2}$ to $\mathrm{UO}_{2+\mathrm{x}}$ oxidation process.

However, the OCPs of both SIMFUEL samples are situated at the onset of the third peak/region where a $\mathrm{U}(\mathrm{VI})$ species is developing. Inspection of Pourbaix diagrams for the uranium- $\mathrm{H}_{2} \mathrm{O}$ system (not shown) reveals that the OCPs of the SIMFUELs in the $\mathrm{pH} 5.6$ $\mathrm{Na}_{2} \mathrm{SO}_{4}$ solution used in the experiments of Figures 1 and 2 lie in the potential region where the dissolution as $\mathrm{UO}_{2}{ }^{2+}$ is expected to begin [12].

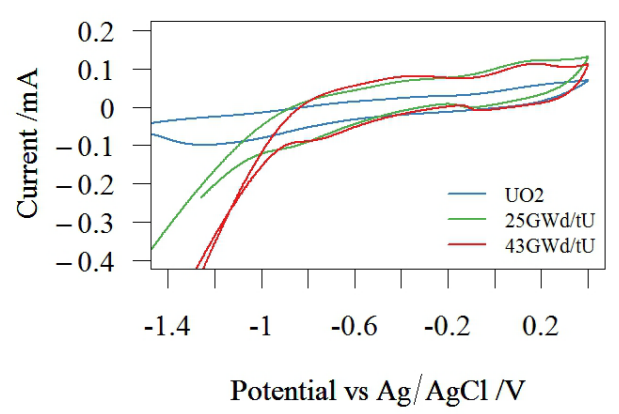

Figure 3. Cyclic Voltammetry of $\mathrm{UO}_{2}, 25$ and $43 \mathrm{GWd} / \mathrm{tU}$ SIMFUELs in simulant pond water.

The above baseline electrochemical experiments were then repeated in simulant pond water solutions of $\mathrm{pH} \approx 11.4$, the results of the $\mathrm{CV}$ experiments being seen in Figure 3. Three common regions were observed in the forward-going sweeps of each voltammogram, which are attributed to the oxidation and dissolution of the surface with the same assignments as in Figure 1. The currents observed in Figure 3 are suppressed compared to those observed in Figure 1. It is possible that the currents are greater in $\mathrm{Na}_{2} \mathrm{SO}_{4}$ due in part to the development of local acidity as a result of hydrolysis of the $\mathrm{UO}_{2}{ }^{2+}$ generated at positive potentials [11].

$$
\mathrm{nUO}_{2}{ }^{2+}+\mathrm{yH}_{2} \mathrm{O} \rightarrow\left(\left(\mathrm{UO}_{2}\right)_{\mathrm{n}}(\mathrm{OH}) \mathrm{y}\right)^{(2 \mathrm{n}-\mathrm{y})^{+}}+\mathrm{yH}^{+}
$$

In the $\mathrm{pH} 11.4$ simulant pond water, this acidity would be neutralized by the presence of the $\mathrm{NaOH}$ used as a corrosion inhibitor. Also in alkaline solution $\mathrm{UO}_{2}{ }^{2+}$ has limited solubility and, again from inspection of the relevant Pourbaix diagrams, the U(VI) generated at higher potentials takes the form of insoluble $\mathrm{UO}_{3} \cdot \mathrm{yH}_{2} \mathrm{O}$ [11] which itself would be expected to precipitate as a current suppressing surface layer.

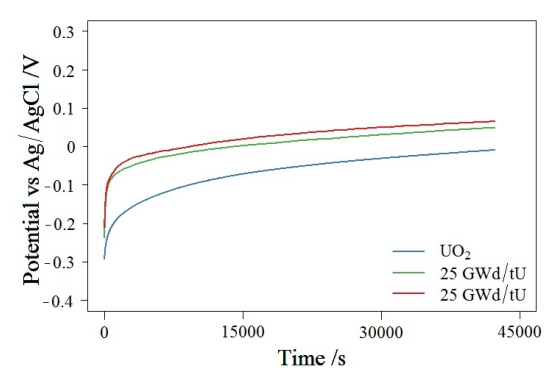

Figure 4. Open Circuit Potential measurements of $\mathrm{UO}_{2}, 25$ and $43 \mathrm{GWd} / \mathrm{tU}$ SIMFUELs in simulant pond water, $\mathrm{pH} \approx 11.4$.

A reduction in the OCPs is also observed under pond water conditions $(\mathrm{pH} \approx 11.4)$, the values recorded for pure $\mathrm{UO}_{2}, 25 \mathrm{GWd} / \mathrm{tU}$ and $43 \mathrm{GWd} / \mathrm{tU}$ being $-0.01 \mathrm{~V}, 0.05$ and $0.06 \mathrm{~V}$ respectively, as shown in Figure 4. On inspection of the CVs of these samples in simulant pond water shown in Figure 3 it can be seen that the OCP of pure $\mathrm{UO}_{2}$ again sits at the onset of the current peak associated with the onset of the $\mathrm{UO}_{2}$ to $\mathrm{UO}_{2+\mathrm{x}}$ oxidation process whereas the OCPs of both SIMFUEL samples sit on 
anodic side of this same wave (i.e. towards potentials where the oxidation to $\mathrm{UO}_{2+\mathrm{x}}$ will be more advanced). Therefore, the OCPs for both SIMFUELs in alkaline pond water lie at potentials negative of those seen in near-neutral $\mathrm{Na}_{2} \mathrm{SO}_{4}$ solutions (see Figure 2) and in the region where a potentially protective $\mathrm{UO}_{2+\mathrm{x}}$-type oxide layer is growing on the surface of the sample.

To show the direct implications of the effect of $\mathrm{NaOH}$ and $\mathrm{pH}$, the OCPs were measured for a $0.5 \mathrm{M} \mathrm{Na}_{2} \mathrm{SO}_{4}$ solution dosed with $\mathrm{NaOH}$ to $\mathrm{pH} \approx 11.4$ see Figure 5 from which it can be seen that the equilibrium OCPs for pure $\mathrm{UO}_{2}, 25$ and $43 \mathrm{GWd} / \mathrm{tU}$ samples are $-0.06 \mathrm{~V}, 0.04$ and 0.06 respectively. These values are almost identical to those found for simulant pond water at the same $\mathrm{pH}$ as shown in Figure 4. These values for $\mathrm{UO}_{2,} 25$ and $43 \mathrm{GWd} / \mathrm{tU}$ samples are all more negative than the analogous readings recorded in neutral electrolyte, Figure 2, illustrating how increasing the $\mathrm{pH}$ decreases the OCPs of all three samples. The equilibrium OCPs recorded from the 25 and $43 \mathrm{GWdtU}$ samples in neutral media in Figure 2 lie on the wave associated with matrix oxidation to $\mathrm{UO}_{2}{ }^{2+}$ in Figure 1. In contrast, the analogous OCPs recorded in pH 11.4 media in Figures 4 and 5 lie at potentials more negative than those where dissolution as $\mathrm{UO}_{2}{ }^{2+}$ would be expected in Figure 3, suggesting that the presence of $\mathrm{NaOH}$ at $\mathrm{pH} 11.4$ suppresses the dissolution as $\mathrm{UO}_{2}{ }^{2+}$.

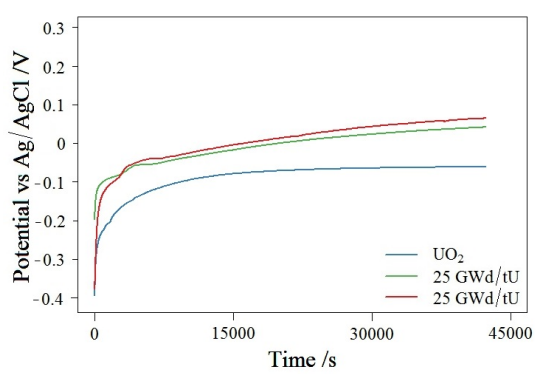

Figure 5. Open Circuit Potential measurements of $\mathrm{UO}_{2}, 25$ and $43 \mathrm{GWd} / \mathrm{tU}$ SIMFUELs in $0.5 \mathrm{M} \mathrm{Na} \mathrm{Na}_{4}$ dosed to $\mathrm{pH} \approx 11.4$ with $\mathrm{NaOH}$.

\section{Conclusions}

These studies report the voltammetric behavior of pure $\mathrm{UO}_{2}$ and AGR SIMFUELs in simulant pond water ( $\mathrm{pH} \approx 11.4)$ and compares these results to their behavior in a simple electrolyte, $0.5 \mathrm{M} \mathrm{Na}_{2} \mathrm{SO}_{4}$, of $\mathrm{pH} \approx 5.6$. The most significant observations are as follows:

- There are lower corrosion currents for all three samples in simulant pond water compared to those seen in the $\mathrm{Na}_{2} \mathrm{SO}_{4}$ solution.

- There is a reduction in the OCP for all samples under pond water conditions. Particularly, the OCP for the SIMFUEL samples moves from a region where active dissolution of the surface may be expected to an area where an oxide layer is developing. It is likely that this oxide layer then protects the surface from dissolution.

These experiments provide preliminary indications that dosing the pond water to a $\mathrm{pH}$ of $\sim 11.4$ provides corrosion protection. Future work will include a series of electrochemical impedance spectroscopy and Raman microspectroscopy studies to elucidate the nature of the above-mentioned protective oxide, and the conducting of analogous experiments on real irradiated fuel at Sellafield to assess how good an analogue these SIMFUELs are for real spent nuclear fuel.

\section{Acknowledgements}

This work is supported by the NNL Lancaster University and the Lloyd's Register Foundation (LRF) via provision of a $\mathrm{PhD}$ studentship for $\mathrm{EH}$ and support for CB. LRF supports the advancement of engineering, and funds research and development that enhances safety of life at sea, on land and in the air.

\section{References}

[1] Thermal Analysis for 63e Storage Rack. 2009, PDL Solutions Europe: PDL-NWP-102910.

[2] B.J. Hands, Long-term storage of AGR fuel: Review of existing data and recommendations for further work. RDR 0786, 1996.

[3] Z. Hiezl et al., Processing and microstructural characterisation of a UO2-based ceramic for disposal studies on spent AGR fuel, J. Nucl. Mat. 456 (2015), pp. 74-84.

[4] N. Rauff-Nisthar, C. Boxall, et al., Corrosion Behaviour of AGR SIMFUELs, ECS Transactions (2015), pp. 85-94.

[5] R.J Wilbraham, N. Rauff-Nistar, C. Boxall et al., Raman studies of advanced gas-cooled reactor simulated spent nuclear fuels, Prog. Nucl. Sci. Technol. 5 (2018), pp.213-216.

[6] Burstall, R.F., Fispin-a computer code for nuclide inventory calculations, UK Atomic Energy Authority Report ND-R-328 (R) , (1979).

[7] S.Sunder, D.W. Shoesmith et al., Anodic Oxidation of UO2: Part I. Electrochemical and X-ray photoelectron spectroscopic studies in neutral solutions. J. Electroanal. Chem. 130 (1981), pp. 163-179.

[8] S. Sunder, D.W. Shoesmith et al., Anodic oxidation of UO2: Part II. Electrochemical and X-ray photoelectron spectroscopic studies in alkaline solutions, J. Electroanal. Chem. 150 (1983), pp. 217-228.

[9] Shoesmith, D.W., Fuel corrosion processes under waste disposal conditions. J. Nucl. Mat. 282(1) (2000), pp. 1-31.

[10]D.W Shoesmith, S. Sunder and W.H Hocking, Electrochemistry of UO 2 Nuclear Fuel in Electrochemistry of Novel Materials: Frontiers of Electrochemistry, J. Lipkowski and P.N. Ross, Editors. VCH Publishers, (1994), pp. 297-338.

[11]H.He et al., Characterization of the influence of fission product doping on the anodic reactivity of uranium dioxide. Can. J. Chem. 85(10) (2007), pp. 702-713.

[12]M.Pourbaix, Atlas of Electrochemical Equilibria in Aqueous Solutions, NACE, (1974), pp. 198-212. 